\title{
ESTÉTICA Y RETÓRICA DE LA INSCRIPCIÓN. LECTURA DE LA IMAGEN-TIEMPO EN SOLARIS, DE A. TARKOVSKI
}

\author{
Antonio AGUILAR GIMÉNEZ \\ Universidad de Valencia \\ antonio.aguilar@uv.es \\ Awake, my sleeper, to the sun, \\ Dylan Thomas. 18 poems.
}

\section{1}

\section{Introducción. Imagen y literatura}

Solaris es un planeta siniestro, puede hacer presentes los fantasmas más ocultos de la consciencia, darles un rostro, puede figurar los lazos entre el arte y la ciencia, entre el sueño y la vigilia. Sus ocupantes han perdido la capacidad de distinguir entre el origen de las imágenes que se les aparecen y las mismas apariciones. Conviven con meras inscripciones que se confunden con otras representaciones artísticas en continuo deslizamiento, llegando a producir un parasitismo incómodo entre géneros. La literatura tampoco escapa de los influjos del planeta. La lectura de un fragmento de Don Quijote en Solaris (Solyaris, Andrei Tarkovski, 1972) da paso a la escena en que Kris y Hari levitan a causa de la ausencia de gravedad mientras la estación espacial realiza una maniobra. Manejan una edición del libro que incluye los grabados de Doré. Detrás de la mesa de la biblioteca, como en un pequeño santuario, cuatro cuadros de Brueghel el viejo. La biblioteca es una gran sala con libros amontonados en las repisas de los muebles, dispuestos entre bustos clásicos griegos, armas de fuego antiguas en las paredes que alternan junto a instrumentos musicales, máscaras y bocetos de dibujos. El resto de libros de la biblioteca no interesan, son suplementos para el libro que vale la pena leer, sólo dejan paso al libro, el único libro que no es basura, según las palabras de Snawrt, uno de los cuatro personajes que intervienen en la escena. Sin embargo, los libros son el sustento de la biblioteca, sin libros no hay biblioteca. El resto de libros con respecto a Don Quijote son como el día para la noche, como la vigilia para el sueño. Podría parecer, por tanto, que estamos ante el ideal del libro, ante el libro absoluto, cerrado, ante la literatura pura, ante la idea de un saber literario que se autodefine y se basta a sí mismo. Nada más ficticio, aun más cuando el pasaje que se lee del libro trata sobre el sueño.

«Mira la serenidad de esta noche, la soledad en que estamos, que nos convida a entremeter alguna vigilia entre nuestro sueño» Cervantes (1994: 1124), dice el caballero a su escudero, al comienzo del capítulo LXVIII, donde ya se prepara para adentrarse en la noche violando las reglas del sueño. Don Quijote se resiste a dormir esta noche y pretende que Sancho también lo haga. Igual sucede en Solaris, 
los ocupantes de la estación espacial han optado por estar siempre despiertos. «Lo importante es no dormirse», insiste Snawrt. La razón es sencilla: los visitantes vienen de noche. Y en efecto sólo veremos a Kris durmiendo en la película, el único que da hospitalidad a la materialización de su consciencia. La capacidad de soñar en Solaris parece estar ligada a cierta creencia en el cambio, en lo que puede llegar de la noche a transformar el presente. En el gesto hospitalario hacia el otro o lo otro por venir. ¿En qué medida la lectura de Don Quijote en esta escena, el injerto literario en el cine no viene a confirmar esta hospitalidad? ¿Se transforma así la literatura en cine, igual que Doré convierte en pintura las andanzas de Don Quijote? ¿Acaso el injerto viene a potenciar las relaciones entre artes o produce más bien cortocircuitos en su lectura?

«El problema es que uno ha perdido el sueño», recuerda Snawrt. Ni Sartorius ni Hari duermen tampoco. Hari no sabe dormir; se acuesta junto a Kris en la misma cama, igual que hicieran cuando estaban casados; cierra los ojos, imita los preludios del sueño, detiene sus movimientos, cambia la excitación por el reposo, pero no sabe dormir. En Solaris los sueños no saben dormir. Don Quijote también impone una resistencia al dormir, o bien utiliza la propia resistencia del sueño:

Cumplió don Quijote con la naturaleza durmiendo el primer sueño, sin dar lugar al segundo; bien al revés de Sancho que nunca tuvo segundo, porque le duraba el sueño desde la noche hasta la mañana, en que se mostraba de buena complexión y pocos cuidados. Los de Don Quijote le desvelaron de manera, que despertó a Sancho y le dijo:

-Maravillado estoy, de la libertad de tu condición: yo imagino que eres hecho de mármol o de duro bronce, en quien no cabe movimiento. Cervantes (1994: 1124).

Sancho se mueve por leyes naturales, duerme toda la noche hasta la mañana. Don Quijote, en cambio, sólo cumple en parte con la naturaleza, sólo duerme el primer sueño, y quiere que de igual manera Sancho pase así la noche, sólo que Sancho se niega, no es ningún religioso para que desde la mitad de su sueño se levante. Su reacción se justifica por su naturaleza, según Don Quijote, Sancho tiene los atributos de una estatua: es de mármol, o de bronce, y por tanto, no cabe en él el movimiento. ¿Por qué hace del escudero una estatua precisamente hablando del sueño? ¿Qué resuena en esta imagen? ¿Qué implicaciones tiene esto cuando se está citando en otro medio, en el cine? ¿Cómo trabaja entonces aquí la cita, cuando sabemos que el cine, por el contrario, es movimiento, movimiento de la imagen y duración en el tiempo? El sueño aparece entonces, por oposición al cine como lo inmóvil frente a lo fluido. Sancho cuando duerme detiene su cuerpo y se convierte en estatua. El sueño da paso a un complejo circuito de relaciones materiales que ponen en cuestión la inmovilidad del sentido en los distintos planos de la obra.

Don Quijote actúa de una manera artificial al apartarse del sueño, igual de artificial que apartarse del sueño junto a la literatura, o igual de artificial que hacer de la noche la literatura. Porque el caballero prefiere velar, y para ello, dará rienda suelta a sus pensamientos y los desfogará en un madrigalete, que afirma compuso en la memoria ${ }^{1}$. Por un lado, al sueño se le resiste con la literatura, que sirve para adentrarse en la noche; por otro, no es casual que Don Quijote afirme que tratará la literatura desde la

\footnotetext{
${ }^{1}$ Don Quijote no es del todo sincero, hace ficción de su afirmación, el madrigal es una traducción de otro incluido en Gli Asolani de Pietro Bembo.
} 
memoria, ni casual ni inocente, aun más cuando el planeta Solaris puede poner en escena, puede poner a trabajar materialmente la memoria. Y así, Don Quijote en su empeño, le reprocha a Sancho su tendencia al sueño, lo quiere a él también despierto, le exige resistencia, que se posicione en la noche. Sancho nunca fue más lúdico respondiendo:

-No entiendo esto -replicó Sancho-; sólo entiendo que en tanto que duermo, ni tengo temor, ni esperanza, ni trabajo, ni gloria; y bien haya el que inventó el sueño, capa que cubre todos los humanos pensamientos, manjar que quita el hambre, agua que ahuyenta la sed, fuego que calienta el frío, frío que templa el ardor, $y$, finalmente, moneda general con que todas las cosas se compran, balanza y peso que iguala el pastor con el rey y al simple con el discreto. Sola una cosa tiene mala el sueño, según he oído decir, y es que se parece a la muerte, pues de un dormido a un muerto hay muy poca diferencia. Cervantes (1994: 1125).

El texto cervantino pone así en funcionamiento dos series antitéticas: el sueño, la inmovilidad, la muerte; frente a la vigilia, la literatura, la memoria. No obstante, de un dormido a un muerto hay muy poca diferencia, afirma Sancho, no hay relación de identidad entre los dos, sino que permanece la diferencia, la misma diferencia que articula las dos series y las vuelve inestables e incluso subversivas. Precisamente las palabras de Sancho son leídas (injertadas) por Kris en la biblioteca, mientras Hari permanece de pie a su lado, una mano sobre su hombro. La lectura produce un inevitable primer quiasmo: Hari es a Don Quijote lo que Sancho es a Kris. Esto es, Hari que no puede dormir se asemeja al caballero que se resiste a la noche, mientras que Sancho se entrega al sueño igual que Kris. Sin embargo, el aspa del quiasmo, por el mismo efecto de lectura realizado desde la noche nunca está quieta, y la diferencia inscrita en las series empieza su trabajo. El sueño de Kris no conduce a la inmovilidad, sino que gracias a su sueño Hari, imagen de la memoria, y por tanto imagen del tiempo, cobra vida y por el contrario vuelve de la muerte. El sueño se sitúa entonces en la diferencia entre la vida y la muerte, igual que Hari, que realmente ni está viva ni muerta, siendo sólo una figura de la memoria. La alegoría de la ficción que se narra en Solaris, a través de la lectura del Quijote, es una alegoría del sueño. Del sueño como lugar de la ficción, pero también del sueño como lugar en el que tiene lugar, en el que acontece, lo más profundo de la consciencia, que viene a cuestionar el mismo estatuto de la ficción. El lugar del sueño en Solaris, al igual que en el fragmento citado de boca de Sancho es un lugar parecido a la muerte, pues de un dormido a un muerto hay poca diferencia. La lectura de este fragmento de la novela viene a unirse al recordatorio de Sartorius sobre la condición humana de Hari. Sartorius le repite que no es humana, que es simplemente una reproducción de la Hari original, de la primera Hari, la que se suicidó hace diez años al sentir que Kris ya no la quería.

-Usted no es una mujer, ni una persona. Entiéndalo de una vez, si es capaz de entender algo. Hari no existe, murió. Usted tan sólo es su reproducción, una repetición mecánica, ¡una copia! ¡Una matriz!

\section{La matriz, el receptáculo, la Khora}

Hari es una matriz, no tiene entidad por sí misma, puede reproducirse, hasta el infinito sin participar de la finitud, es simplemente copia, el lugar de la inscripción de otro cuerpo, la pura diferencia con respecto a la mujer original. Hari, como topos, es lugar de la reproducción en el sueño, 
lugar en el que los muertos se parecen demasiado a los que duermen, lugar en el que los que los que duermen copian a los muertos. Según Platón, la Khôra es el lugar de inscripción original de las formas. Este lugar de tercer género antes de la distinción entre el mundo «real» (ilusorio) y el mundo de las ideas (reales) que Platón puede concebir sólo como un desencadenamiento de «metáforas» se denomina, entre otras cosas, nodriza, matriz, receptáculo, madre. En el Timeo la Khôra aparece como un tercer género, en Solaris, Hari es Khôra como antonomasia del sueño. Por este motivo el trabajo del sueño se muestra como una constante tensión entre la figura-imagen y la figura-matriz. «La figuraimagen, la que veo en al alucinación o el sueño, que me viene dada por el cuadro, la película, es un objeto colocado a distancia, tema; pertenece al orden de lo visible: trazado revelador», Lyotard (1979: 274). La figura-imagen como Hari, como cualquier de los visitantes es esquema, es la manifestación visible del deseo, la realización en imagen de lo más íntimo de la consciencia. Espíritu absoluto materializado, congelado en su tránsito. La figura-forma está presente en lo visible, y en este caso en lo tangible. Según Lyotard, por el contrario, la figura-matriz es invisible por principio, objeto de represión originaria, mezcla inmediata de discurso, fantasma «originario». Sin embargo, es figura, no estructura, porque de entrada es violación del orden discursivo, violencia hecha a las transformaciones autorizadas por este orden. El orden discursivo de lo real se rompe en Solaris con la aparición de los visitantes, con ellos se pone en cuestión lo otro del discurso y de la inteligibilidad, incluso de la representación. Afirma Lyotard, la matriz fantasmática, en lugar de ser un origen, demuestra lo contrario, que nuestro origen es una ausencia de origen y que todo lo que se presenta como objeto de un discurso originario es una figura-imagen alucinante, situada precisamente en este no lugar inicial. Hari, como matriz, lo que viene a cuestionar es el mismo lugar la imagen del hombre y de su representación, que además de ser inscripción en la memoria lo es en el sueño, en la noche.

El sueño confina con la región donde reina la pura semejanza. Allí todo es semejante, cada figura es otra, es semejante a la otra, e incluso otra, y ésta a otra. Se busca el modelo original, quisiéramos ser remitidos a un punto de partida, a una revelación inicial, pero no la hay: el sueño es lo semejante que remite eternamente a lo semejante. Blanchot (1992: 256).

La figura de Hari se entremezcla durante todo el largometraje con la de la madre del protagonista. Hari recordémoslo es Khôra, copia, madre, matriz. Hari es copia, es la semejanza que aparece en la noche, es la copia pura sin origen. La madre ${ }^{2}$, el simulacro de la madre, que recoge al hijo sacrificado por la imagen del hombre y lo eleva en el momento de gravedad cero de la nave. Suena un preludio coral de Bach. Kris y Hari flotan en la biblioteca, él apoya su cabeza sobre ella que lo recibe.

\footnotetext{
${ }^{2}$ Laura Mulvey, en un clásico artículo sobre la posición de la mujer en el cine desde la mirada falocéntrica, comenta que la función de la mujer en la formación del inconsciente patriarcal tiene dos facetas; la primera simboliza la amenaza de castración, después como consecuencia introduce al hijo en lo simbólico. Una vez que esto se ha cumplido, añade Mulvey, «su sentido en el proceso termina y no permanece en el mundo de la ley y del lenguaje más que como una memoria que oscila entre la memoria de la plenitud maternal y la memoria de la carencia» (Mulvey, 1985: 2). Claro que Hari, no es sólo una mujer, es asimismo Khôra, imagen, matriz y receptáculo, con lo cual quiebra la escoptofilia entendida como exhibicionismo o represión. No obstante Hari se vuelve ex mujer, recuperación de la mujer, madre, y símbolo de la maternidad. Y si bien oscila entre la memoria de la plenitud maternal, siempre lo hace como copia, como lugar desdoblado y cuestionador del origen del sentido de la madre. Su memoria como copia es artificial, fragmentaria, su faceta reproductora se limita a la puesta de nuevo en circulación de una imagen, ni siquiera suya, sino de la memoria.
} 
Escultóricamente forman una piedad, figura constante en la filmografía tarkovskiana. La piedad, a lo largo de la historia del arte nos muestra la representación del dolor de la virgen María al sostener el cadáver de Jesucristo descendido de la cruz. En el total de la obra de Tarkovski, el sacrificio es un motivo recurrente, la abnegación, de un protagonista masculino que se entrega al cuerpo de la mujer, el cual actúa como receptáculo de amor y perdón. Sólo a través del sacrificio ${ }^{3}$ se puede llegar al amor, y el amor es un acto además de artístico, de comprensión del Todo, un acto político, de lucha y liberación. Tarkovski erige una piedad como un grupo escultórico en movimiento, y aquí es donde arranca la potencia de la propuesta, sobre todo si no dejamos de tener presente que estamos ante una obra de arte cinematográfica.

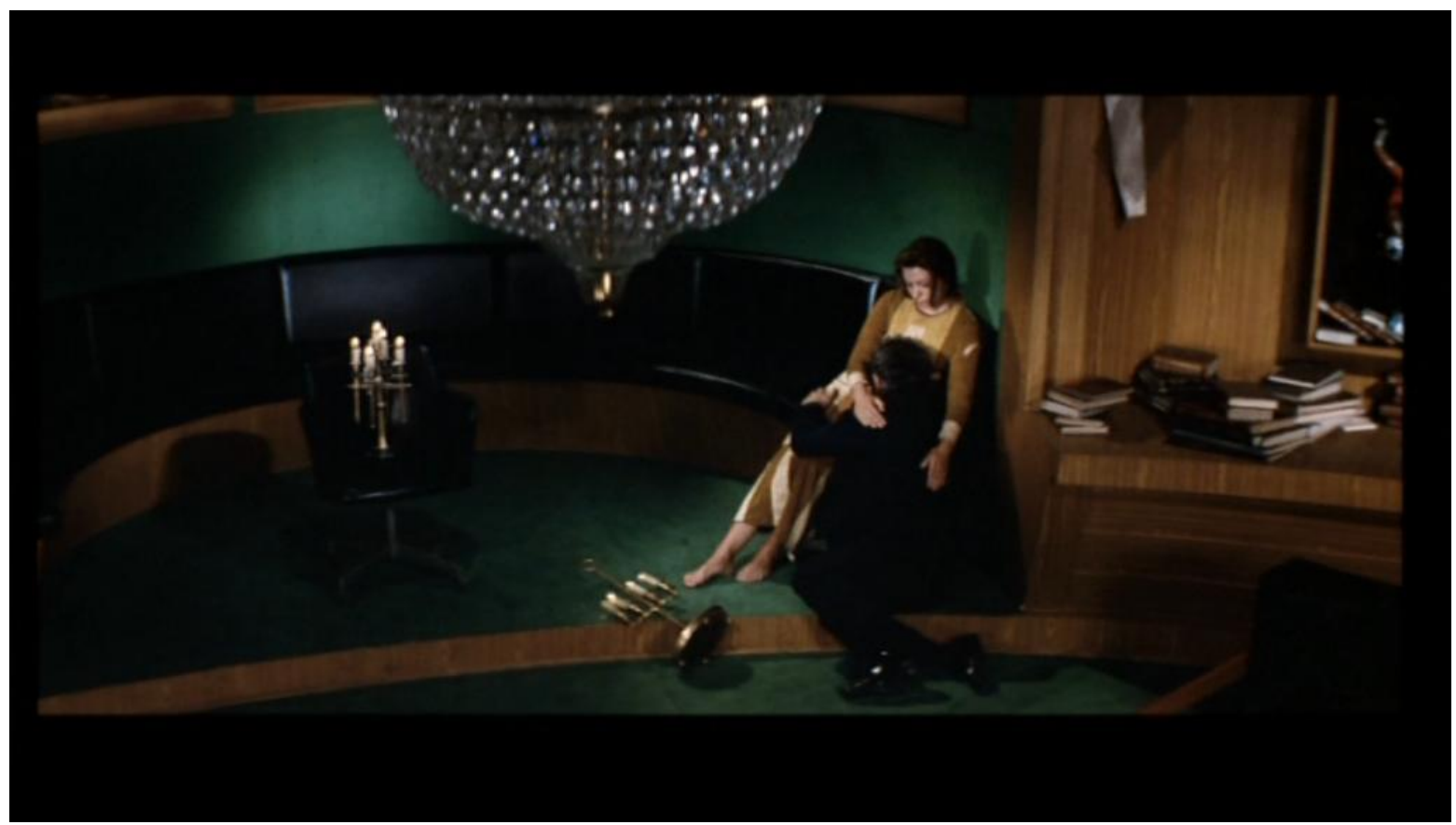

Deleuze y Guattari en ¿Qué es la filosofía? definen la obra de arte como un bloque de sensaciones, esto es, como un compuesto de perceptos y afectos. La obra de arte, afirman, es un monumento, pero no es en este caso lo que conmemora un pasado, sino un bloque de sensaciones presentes que sólo a ellas mismas deben su propia conservación, y otorgan al acontecimiento el compuesto que lo conmemora. El acto del monumento no es la memoria, sino la fabulación. ¿Qué significa esto? Por un lado, un intento radical de responder a la cuestión heideggeriana del arte como imagen desveladora del mundo; por otro, la puesta en marcha de una filosofía de la inmanencia donde sensaciones y perceptos convierten a la obra de arte en un ser de sensación, cuya existencia está en su materialidad. El gesto, evidentemente supone un alejamiento de cualquier perspectiva fenomenológica tradicional. Según proponen se pueden caracterizar tres

\footnotetext{
${ }^{3}$ «El hombre moderno no quiere sacrificarse, a pesar de que la verdadera individualidad sólo se alcanza por medio del sacrificio. [...] Si hablamos de inclinarse hacia la belleza, de que la meta del arte, surgido por el ansia de lo ideal, es precisamente ese ideal, no quiero decir con ello que el arte deba evitar el "polvo" de lo terreno... Todo lo contrario: la imagen artística es siempre un símbolo, que sustituye una cosa por otra, lo mayor por lo menor. [...] Un sustitutivo. Lo infinito no es materializable, tan sólo se puede crear una ilusión, una imagen» Tarkovski (2004: 62).
} 
grandes tipos monumentales: la vibración (sensación simple duradera); el abrazo (dos sensaciones que resuenan una en la otra); el retraimiento (dos sensaciones que se alejan). La escultura presenta estos tipos casi en estado puro, con sus sensaciones de piedra. La escultura entonces es el modelo del monumento, pero ¿qué supone presentar una escultura en cine? ¿Qué ocurre cuándo una escultura tiene movimiento? ¿Se esculpe entonces el tiempo, tal y como quería Tarkovski?

\section{La inscripción, el tiempo, la imagen}

La poética cinematográfica de Tarkovski, ha comentado Luca Governatori (2002: 84), se situaría en el cruce de tres artes: la escultura, la música y la pintura. El resultado sería una escultura de lo invisible (del tiempo) por el movimiento musical de lo visible. Es Justamente aquello sobre lo que Deleuze trabaja en La imagen movimiento y en La imagen tiempo. Es extraño el poco tiempo que Deleuze (1983: 60-61) dedica para hablar de Tarkovski, tan sólo dos páginas, del total de los dos volúmenes, donde curiosamente no se refiere a ninguna de sus películas, sino a un texto titulado «De la figura cinematográfica». Deleuze retoma a través de este texto la problemática fundamental entre plano y montaje. Para Tarkovski lo esencial es cómo el tiempo discurre en el plano, cómo se puede llegar a mostrar la tensión del tiempo en el plano. Aparentemente, dice Deleuze, Tarkovski parece decidirse por el plano ante la dicotomía clásica montaje o plano, pero esto realmente no es más que una apariencia. En este punto se acerca también a Bazin (2004: 48-54) al rechazar el montaje como operación fundamental para fijar el tiempo puesto que dota al movimiento de artificialidad y le da cierta cualidad analítica que el plano, y en especial el plano secuencia, no comparten por separado. Sin embargo, la imagen-movimiento sin el montaje queda amorfa, el montaje es una forma de constituir una imagen indirecta del tiempo. El plano en tanto que imagen-movimiento, como se ha visto, tiene dos caras: una vuelta hacia el encuadre donde se establece el movimiento de traslación en el espacio entre las partes; otra vuelta hacia el montaje donde se expresa un cambio absoluto en la duración, como sostiene Marrati (2004: 31-51). El tiempo como cambio cualitativo del Todo está así a cargo del montaje. El montaje, como representación indirecta del tiempo, se remite a la fuerza en la sucesión de imágenes, mientras que el plano determina la fuerza del tiempo en la imagen. Por lo que desde la perspectiva deleuziana, y a través de Tarkovski, no se trata tanto de oponer montaje y plano sino de articular a través del montaje ritmos temporales diferentes. Tarkovski sería entonces una muestra de la consciencia de la crisis de la imagen movimiento, y de la aparición de la imagen tiempo.

Deleuze provocativamente insiste, el cine no es un lenguaje ${ }^{4}$, ni una lengua, y los intentos de estudiarlo aplicando modelos lingüísticos están condenados al fracaso, puesto que olvidan el componente temporal de la imagen en movimiento. Deleuze propone una desnaturalización de la lectura cinematográfica, fundamentada precisamente en una crítica a la naturalización del signo lingüístico. Como Lyotard (1979: 292) indica, la naturaleza habla por imágenes en tanto que hay,

\footnotetext{
${ }^{4}$ «Le cinéma n'est pas langue, universelle ou primitive, ni méme langage. II met á jour une matière intelligible, qui est comme un présupposé, une condition, un corrélat nécessaire á travers lequel le langage construit ses propres «objets» (unités et opérations signifiantes)»(Deleuze, 1983: 342).
} 
adecuado en el orden sensible, el sitio de un ver. El lenguaje empieza con la pérdida de la naturaleza. El sistema de signos cinematográfico empieza con la imagen y el movimiento, fuera de la espacialización del tiempo. Esto es una apuesta por mantenerse al margen de la ontología heideggeriana, y por lo tanto de cualquier hermenéutica, manteniéndose en los márgenes de la alternativa de Bergson.

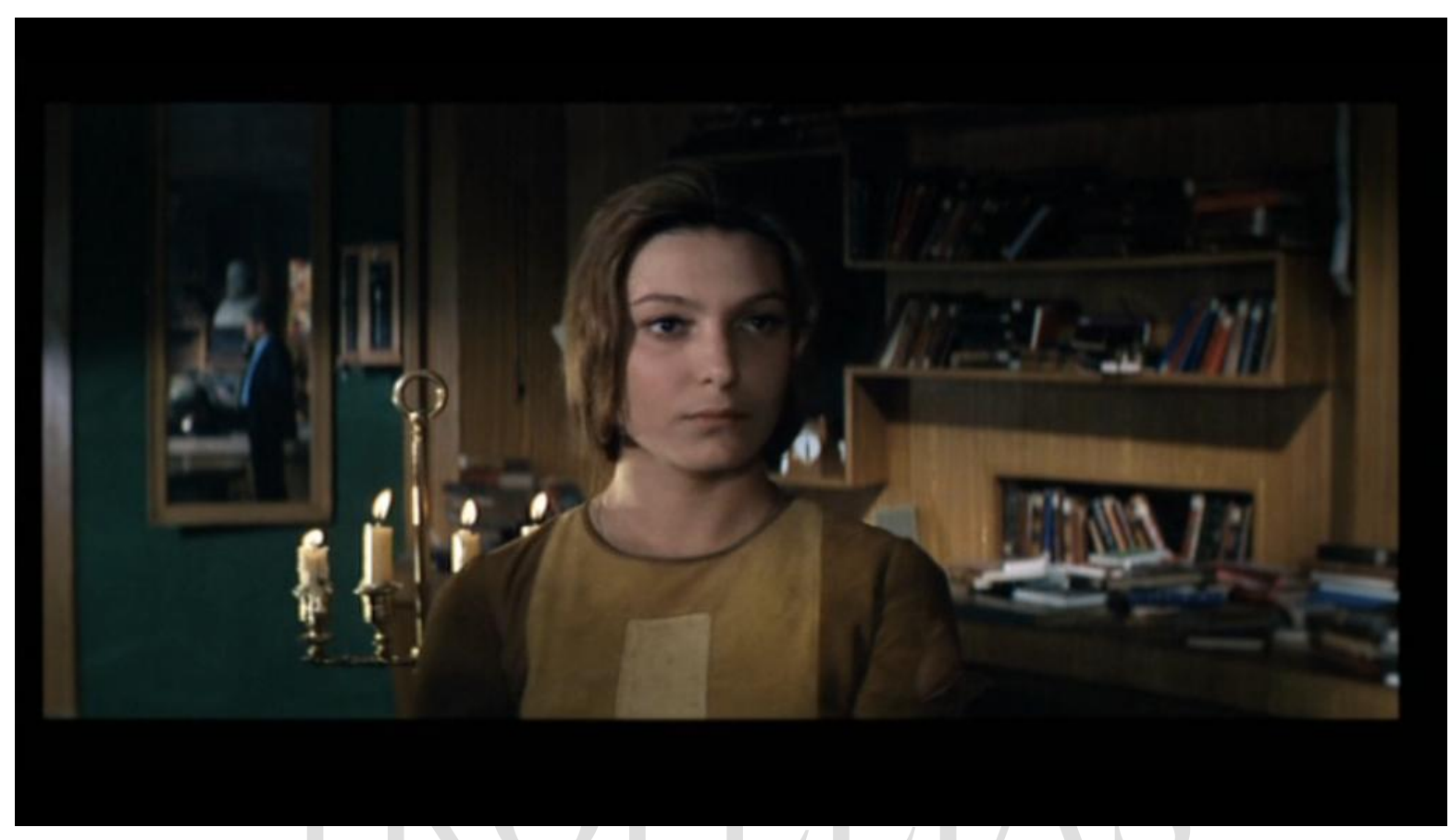

Mientras flotan, al fondo, cuatro cuadros de Brueghel el viejo. Kris, con su gesto de renunciación, ha pedido perdón a Hari; en esta alegoría, es un modelo de amor el que puede salvar a la humanidad. Renunciación ${ }^{5}$ por un lado a entender la dimensión temporal de su existencia como sujeto, y por otro, renunciación a este intento mismo. Renunciación, en definitiva, a reconciliar signo y significado, a sucumbir a la tentación de poder leer la propia historia.

La secuencia continúa en la biblioteca. Cuando Kris vuelve corriendo, tras acompañar a Snawrt, encuentra a Hari sentada en la mesa. Se encuentra de espaldas a él, y mientras fuma con parsimonia, observa atenta los cuadros de Brueghel, tiene el libro de Don Quijote a su lado todavía. Hari apoya una mano en él mientras sigue su contemplación. Kris avanza sudoroso. Lo vemos en un plano en el que en la pared de la sala hay una trompeta, en el siguiente hay dos pistolas también colgadas, antítesis aparente. La cámara se vuelve desde Kris hacia ella y la vemos mirando de frente, sólo que a su espalda un espejo devuelve la mirada de Kris que la mira. El siguiente plano corresponde al cuadro de Brueghel Cazadores en la nieve. Algo ha cambiado en Hari, cuanto más tiempo está en la nave más humana se vuelve, y esta transformación, esta personificación progresiva depende de la imagen unida al recuerdo. $\mathrm{O}$ dicho de otra manera, cuando aparece ${ }^{6}$ Hari por primera vez es únicamente imagen-movimiento,

\footnotetext{
${ }^{5}$ Ver Mizimura (1985).

${ }^{6}$ Aparecer, frecuentar, anunciar, revelar, son acciones propias de los espectros. Un espectro es la imagen de una persona muerta. Un espectro solar, en términos físicos, es el producido por la dispersión de la luz del sol. Tratamos de imágenes
} 
mientras que toma contacto con el mundo, mientras acontece, se va tornando imagen-tiempo. A medida que va adquiriendo recuerdos, o a medida que experimenta el tiempo, la imagen como recuerdo, Hari se hace casi humana ${ }^{7}$, pues de un humano a Hari hay muy poca diferencia. Casi es Real, en sentido lacaniano, se acerca a la cosa, como sostiene Žižek (1999).

Deleuze utiliza a Bergson de la misma manera que Tarkovski a Brueghel. Bergson distingue dos tipos de reconocimiento: uno, automático, que tiene como fin un uso útil, pragmático; otro, caracterizado como reconocimiento atento, aquél que se detiene en el objeto y lo encuadra subrayando sus aspectos. En uno, percibimos de la cosa una imagen sensoriomotriz; en el otro, constituimos de la cosa una imagen óptica (y sonora pura), hacemos una descripción, Deleuze (1983: 62). ¿Cómo conciliar, sin embargo, estos dos extremos? La imagen en el reconocimiento atento no se prolonga en movimiento, pero en cambio, entra en relación con una imagen-recuerdo. Lo importante de esta aportación, tomada de nuevo de Bergson, es que pone en relación lo real y lo imaginario, lo físico y lo mental lo objetivo y lo subjetivo, la descripción y la narración, lo actual y lo virtual. Oposiciones todas ellas que no dejan de repetirse a lo largo de todo el film de Solaris. Este tercer término parece actuar como cuña ente los pares de las oposiciones. La imagen recuerdo se sitúa entre el sueño ${ }^{8}$ y la vigilia, entre la realidad y la ficción, entre la consciencia y la materia. Se establece un circuito entre cada aspecto de la cosa percibida y un recuerdo. Cada circuito crea y borra un objeto en un doble movimiento de creación y pegado. De este modo la imagen pura de la descripción es una imagen actual, pero que en lugar de prolongarse en movimiento se une con una imagen virtual produciendo el circuito. Las imágenes-recuerdo no intervienen más que accidentalmente y secundariamente en el reconocimiento automático, aunque es esencial para el reconocimiento atento. Este tipo de imágenes se aprovecha de la separación, se inserta. De este modo la subjetividad toma entonces un nuevo sentido temporal y espiritual: lo que se «añade» a la materia, y no lo que la distiende, Deleuze (1983:66-67). El modelo de este proceso sería el flash-back, procedimiento convencional, extrínseco. En su esencia misma es voz, que habla o murmura, y que cuenta lo que ha pasado. A través de Hari vemos aparecerse lentamente el pasado de Kris, no porque ella se lo recuerde, ella no puede recordar, es la propia imagen recuerdo, sino porque en su dimensión material abre la brecha temporal y espiritual que mueve a Kris

compuestas de luz, que son las propias del cine, en un planeta llamado Solaris, que dispersa su centro. Sobre los efectos del sol en la metáfora ver Marges de la philosophie, Minuit, de Jacques Derrida; acerca de la importancia del espectro según Derrida ver, sobre todo, Spectres de Marx.

${ }^{7}$ La evolución de Hari hacia la personificación y el cuestionamiento de lo que esto supone corresponde con lo que Deleuze ha llamado la inversión del simulacro. Esta operación va más allá de la mera inversión de jerarquías, en este caso, humano frente a no humano; copia frente a original; arte frente a naturaleza. Según Deleuze, «el simulacro no es una copia degradada; oculta una potencia positiva que niega el original, la copia, el modelo y la reproducción, por todo ello se muestra que, en realidad, no hay jerarquía posible. De esta manera la semejanza se dice de la diferencia interiorizada; y la identidad de lo Diferente como potencia primera. De las dos series divergentes, al menos, interiorizadas en el simulacro, ninguna puede ser asignada como original, ninguna como copia» (Deleuze, 1994: 263).

${ }^{8}$ Para de Baecque, el espacio del sueño es un espacio doloroso, necesario al despertar de los sentidos y a su comunión con los elementos naturales. El espacio soñado, añade en tono freudiano, es el de la analogía y la correspondencia (véase De Baecque, 1989: 84-85). El sueño sin embargo, en Tarkovski, poco tiene que ver con algo que se pueda llamar «natural», esto supone confundir la imagen con su referencia. Las imágenes naturales en el cine de Tarkovski son, en cualquier caso, pura plegaria. 
a intentar superar ${ }^{9}$ su pasado. Así como Deleuze comenta que en Mankiewicz este papel espiritual de la memoria hace aparecer a una criatura proveniente del más allá: el fantasma, podemos constatar que en Solaris el fantasma rebosa materialidad. No obstante, el fantasma, las apariciones, los visitantes, como los llaman en la estación espacial, sólo vienen de noche, durante el sueño. Esto es lo que Hari no podrá hacer en ningún momento, soñar, auque se entremezcle con las imágenes del sueño o del recuerdo de Kris, aunque no deje de mostrar los efectos del arte.

Después de hablar de las imágenes recuerdo, Deleuze se ocupa de las imágenes sueño. La diferencia entre ambas es que el recuerdo es una imagen virtual asociada a la percepción, mientras que la imagen sueño se asocia a percepciones difusas que durante el acto de dormir escapan a la consciencia. Por otro lado la imagen virtual que se actualiza en el sueño no lo hace directamente, sino que lo hace en otra, y esta en otra, hasta el infinito. El sueño, recalca Deleuze (1983: 78) no es una metáfora, sino una serie de anamorfosis. La anamorfosis permite leer dos figuras a la vez sin posibilidad de decisión, suspende la visión en puro movimiento. Hari en tanto que figura anamórfica lleva en sí el rastro de otras imágenes asociadas al pasado. Como huella de un doble movimiento lejos de reconciliar dos momentos señala más bien la hendidura entre ambos. Porque si bien las apariciones llegan de noche, en el sueño, en la noche del sueño, Hari no es capaz de dormir, ni de soñar. La personificación del sueño no sueña, y Kris, que sueña, confunde el sueño con su pasado. Metz (1977: 91) explica que el dormir verdaderamente pleno (que apenas existe) sería un régimen psíquico en cu yo interior dormirían todas las instancias. Se puede hablar de «dormir pleno» siguiendo una línea relativa y práctica en dos circunstancias: cuando el sueño no tiene ninguna consciencia de ser sueño, y cuando el dormir carece de sueños. Vemos que las dos premisas se incumplen en Solaris dobladas en anamorfosis: Hari no quiere ser sueño, el dormir va irrevocablemente asociado al soñar. Y de igual manera, Metz, preocupado por trazar las diferencias entre el cine y el sueño, afirma que, frente al sueño, que se halla más cogido por el principio de placer, el estado fílmico se basa fundamentalmente en el principio de realidad. Sin embargo, donde Metz resulta más revelador es cuando afirma que «la historia del sueño es una historia pura, una historia sin relato» Metz (1977: 110). ¿Qué cuenta entonces una historia pura ${ }^{10} ?_{¿}$ Y es esta historia que cuenta Hari realmente pura? ¿Sería la historia pura aquella que únicamente reflejara el tiempo? En ese caso sería pura la historia de Hari, que realmente, y por muy poca diferencia, es la historia de Kris Kelvin?

\footnotetext{
${ }^{9}$ Superación en sentido hegeliano como Aufhebung, puesto que como vemos a lo largo de la película, Kris busca una reconciliación con el padre, a través de la mujer, como comunión con el espíritu absoluto. En la lectura derridiana de Hegel se muestra cómo esta superación llega también a través del sacrificio: «La position du père, la filiation telle que nous venons de la lire, s'interprète aussi en vérité comme position du père mort. La vie de l'esprit comme histoire est la mort du père dans son fils. La relève de cette mort a toujours le sens d'une réconciliation : la mort n'aura pu être qu'un acte libre et violent. L'histoire est le procès d'un meurtre. Mais ce meurtre est un sacrifice : la victime s'est offerte. Scandale auquel un tribunal fini ne peut rien comprendre: une victime aurait ainsi tendí aux meurtriers, en même temps que son corps, l'instrument du crime» (Derrida, 1974: 104).

${ }^{10}$ La lectura de Deleuze del cine corresponde más bien con este concepto de historia pura, su lectura pierde la carga de inmanencia cuando lee no materialmente los relatos del cine, y utiliza los relatos para suplementar la historia.
} 


\section{A modo de conclusión. La imagen en la imagen}

Cuando la imagen óptica actual cristaliza con su propia imagen virtual se da la confusión de lo real y lo imaginario. Es una ilusión objetiva, que no suprime la distinción de las dos caras, sino que la vuelve inasignable. Para Deleuze, el caso más conocido es el espejo. Así pues, lo que cambia del «cine clásico» al «cine moderno» es que el tiempo se vuelve una apuesta explícita en el que se crean nuevas disposiciones de imágenes. La representación orgánica se deshace, la imagen cristalina la reemplaza. En el régimen cristalino, por oposición al régimen orgánico, lo real se encuentra separado, cortado, de sus conexiones lógicas, legales, produciendo una anamorfosis continua. El régimen orgánico, por el contrario, es el lugar de las conexiones, causales y lógicas, donde lo real se distingue de lo imaginario como pura aparición.

El espejo es un medio clásico de producir imagen cristal. En Solaris, el espejo sólo es un índice de la complejidad del tratamiento de las imágenes cristal. De vuelta a la biblioteca, Kris encuentra a Hari mirando absorta un cuadro ${ }^{11}$ de Brueghel; ahora Hari, fuma, recupera antiguos hábitos. Kris se pone casi delante de ella, la cámara en posición subjetiva nos muestra a Kris mirándola cómo contempla el cuadro. En la entrada de la biblioteca, al lado de la puerta, hay un espejo. Mientras Kris deja su mirada en Hari que mira la pintura, el espectador reconoce a Kris en el espejo. Kris, por lo tanto, aparece, por si todavía había alguna duda como imagen cristal. Ya no es sólo Hari, la que pone en cuestión la dualidad sueño-realidad, presente-pasado, recuerdo-percepción sensoriomotriz, espíritumateria, ciencia-arte ${ }^{12}$, vemos que en realidad todo sucede alrededor de las vacilaciones de Kris Kelvin, y de su consciencia. Todo nos devuelve a la misma materialidad de la imagen y el movimiento aberrante de la misma en la formación de una temporalidad.

De la imagen del espejo de Kris, la cámara se desplaza hacia los Cazadores en la nieve de Brueghel. Se mueve por la pintura, primero de izquierda a derecha, mostrándonos unos arbustos, las piernas de los cazadores, unos perros de caza olisqueando por la nieve, fragmentos; luego la cámara sube hacia el campanario abriendo así a un plano general en el que vemos diminutas figuras patinando en un lago helado. Tras la aparición de la iglesia llegamos a un momento fundamental, una superposición de planos en movimiento del mismo cuadro. La iglesia permanece inmóvil, mientras que sobre él empieza a transcurrir el travelling de una pequeña casa en la nieve con hombres

\footnotetext{
${ }^{11}$ García Berrio y Hernández hablan de endorreferencialidad estética para los textos artísticos de Miró asociada a la modalización secundaria de Lotman. Oponen el lenguaje mironiano a otro «tipo de lenguaje dominado por la modalidad lógica de los lenguajes naturales, al menos en la dimensión «estándar» lógico-comunicativa de los mismos. Si acaso, el lenguaje mironiano, que es pura metáfora de lenguaje, alcanza a serlo en virtud de su condición autorreferencialmente poética» García Berrio (1988: 31). Así pues se deduce que los lenguajes naturales sí que permiten una lectura limpia y referencial, Tarkovski demuestra que esto no es así; Deleuze que el cine no es un lenguaje.

12 Arte, ciencia, filosofía o literatura son las obsesiones del cine tarkovskiano. «Lo que define el pensamiento, las tres grandes formas del pensamiento, el arte, la ciencia y la filosofía, es afrontar siempre el caos, establecer un plano, trazar un plano sobre el caos. Pero la filosofía pretende salvar lo infinito dándole consistencia: traza un plano de inmanencia, que lleva a lo infinito acontecimientos o conceptos consistentes, por efecto de la acción de personajes conceptuales. La ciencia, por el contrario, renuncia a lo infinito para conquistar la referencia: establece un plano de coordenadas únicamente indefinidas, que define cada vez unos estados de cosas, unas funciones o unas proposiciones referenciales, por efecto de la acción de unos observadores parciales. El arte se propone crear un finito que devuelva lo infinito: traza un plano de composición, que a su vez es portador de los monumentos o de las sensaciones compuestas, por efecto de unas figuras estéticas». Deleuze y Guattari (2001: 199).
} 
trabajando. La cámara sigue avanzando hasta el bosque, donde de nuevo hay otra superposición, esta vez unos cuervos suspendidos en el viento. Ahora la cámara avanza en dirección a la izquierda de la pantalla, y nos lleva hacia la copa de un árbol sin hojas, seguimos bajando lentamente por el tronco hasta otra vez la nieve, y el lago, y un camino por el que avanza un carro. De nuevo el mismo árbol, con la cámara que vuelve, y finalmente unos pastores que avanzan por la nieve desde lo alto de una colina desde la que se divisa toda la escena. Lo siguiente es un plano ya fuera de la pintura de un niño jugando en la nieve, y contemplando un paisaje arbóreo similar al de Brueghel. El niño (Kris en la infancia) está de espaldas, en el momento que se gira vemos a Hari en la biblioteca contemplando el cuadro. Kris mira el cuadro y la mira a ella. Después empieza la levitación.

La pantalla destruye radicalmente el espacio pictórico, afirma Bazin (2004: 212-213). La temporalidad del cuadro es geológica, se desarrolla en profundidad, mientras que en el cine, gracias al montaje, es horizontal, geográfica. Hemos visto que para Bergson el reconocimiento automático o habitual es el que opera por prolongación, es el tipo de reconocimiento sensoriomotriz que proporciona efectos útiles en la percepción. Se forma a través del movimiento horizontal de asociaciones en la percepción, de un objeto a otro en el mismo plano. Bazin, otorga al cine la cualidad de la horizontalidad, que viene dada por el montaje, mientras que Deleuze encuentra la imagen sensoriomotriz horizontal, orgánica, al contrario que la imagen pura que es físico-geométrica, inorgánica.

Si trastocando el proceso pictórico, añade Bazin, se inserta la pantalla en el marco, el espacio del cuadro pierde su orientación y sus límites para imponerse como indefinido. Puesto que Tarkovski además de desbordar el marco del cuadro, al introducirlo en la pantalla, le añade movimiento, consigue trasladar el tiempo del cine ${ }^{13}$ a la pintura. Así, por un lado, produce la ilusión de la narratividad y por otro la encadena a la secuencia anamórfica de la reconstrucción del pasado de Kris ${ }^{14}$ con lo que se produce una afirmación y una negación de la narración al mismo tiempo. El acontecimiento ${ }^{15}$ narrado es el de la propia incapacidad para clausurar la lectura. Convierte así el espacio de la descripción pictórica en un espacio inorgánico, aberrante, en el que se sucede la superposición de planos (espacio hojaldrado). No es casual entonces, que Tarkovski, superponga planos de la pintura de Brueghel y los mantenga contrastados mientras la cámara se desplaza.

\footnotetext{
${ }^{13}$ El concepto de «cronotopo» de Bajtín incide sobre la materialización del tiempo en espacio. Para una lectura de Tarkovski desde este concepto véase Turovskaya (1989).

${ }^{14}$ No es sólo como Carlos Señor (1994: 125) que «Tarkovski hace que varias formas temporales se fundan en un mismo continuo fílmico, narrativo, para conseguir plasmar en imágenes todo el proceso mental de Kelvin», sino que Tarkovski está hablando de una fundación de la subjetividad como tiempo puesto en escena en el cine.

${ }^{15}$ Para Arheim (1990: 131) el cine se especializa en la presentación de acontecimientos. Muestra cambios en el transcurso del tiempo. Lo que tiene lugar en Solaris es sobre todo una pregunta sobre el lugar del arte, sobre la posición del arte ante la materia y el espíritu.
} 


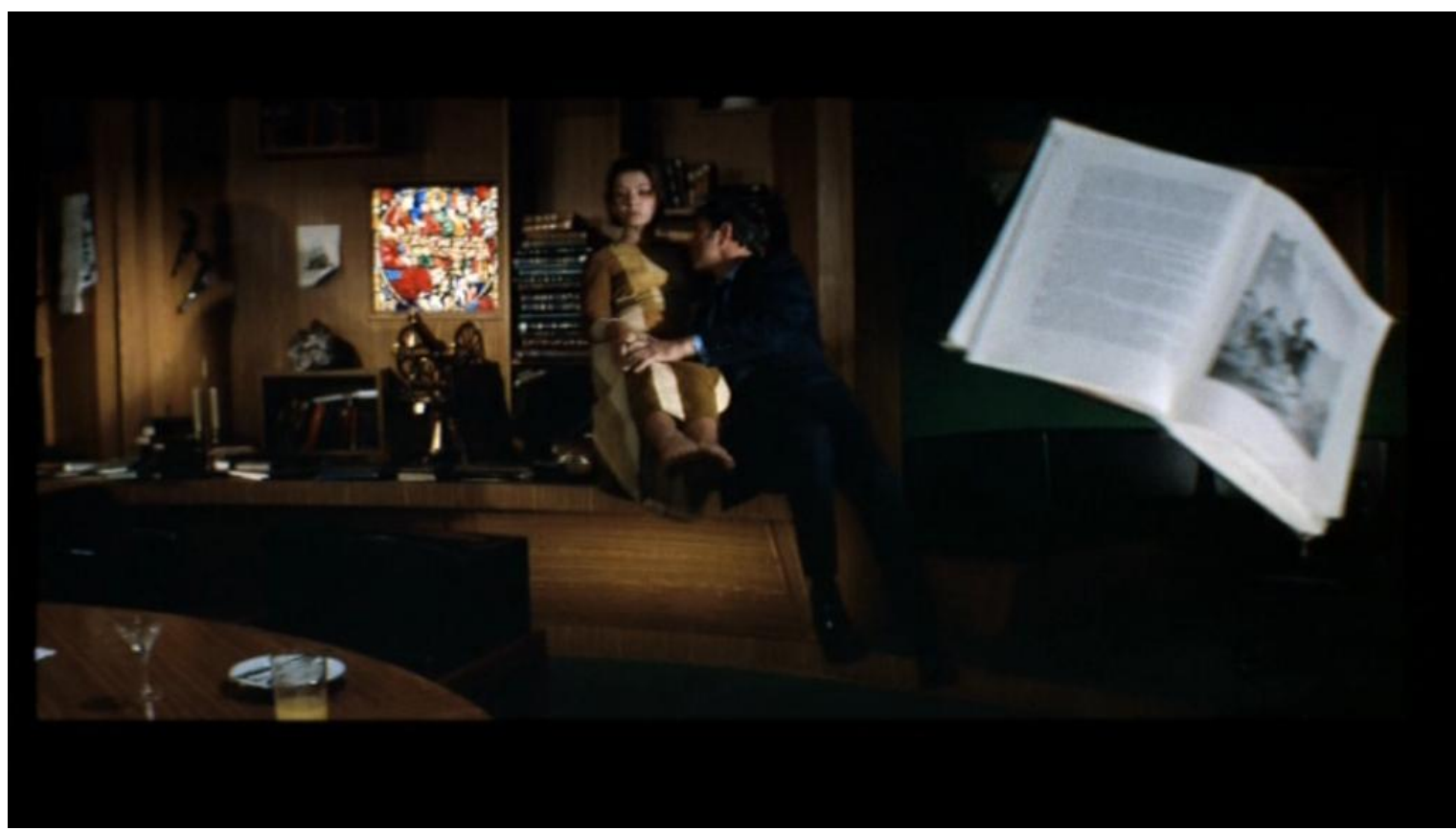

Mientras se elevan, Kris se apoya en ella. Hari pasa el brazo por su hombro y lo atrae a su regazo protector. Después él busca su mano. Pasa el Quijote flotando frente a ellos, abierto por la ilustración de Doré. Vuelven las escenas de nieve de Brueghel. Y a continuación ellos levitando. Sin embargo hay un gesto de Hari, un movimiento de su mano, que sirve para continuar el raccord de la cámara por el cuadro hasta ellos, y que en cierto modo es inquietante, porque ella misma parece la continuación del cuadro y de los dos cuerpos que flotan sobre la biblioteca. Hari le acaricia la cabeza, y la recibe en su seno con calma. Vuelve el cuadro de Brueghel, ahora una vista sobre los árboles, y seguidamente ellos dos ya en el suelo, Kris con la cabeza hundida en su seno, en actitud de arrepentimiento, de demanda de perdón. Ella inclina el cuello y le besa la cabeza como donación de amor. La piedad que forman descansa ahora en tierra, en el suelo de la plataforma espacial. Este acto de descenso, este movimi ento es aprovechado por la cámara para, en el siguiente plano, mostrarnos desde un rápido picado al niño que ya apareció antes, ahora haciendo una pequeña hoguera en la nieve. La levitación no sólo ha sido una pérdida de gravedad, también ha consistido en un viaje por el arte y por las inscripciones de la memoria, por el camino del arte hasta la memoria y el sueño. Pues si bien Hari se presentaba como prosopopeya de la memoria, también lo es del arte, y como prosopopeya da un rostro, pero también, al mismo tiempo, desfigura .

Pero, como el sueño, el arte está más allá de la memoria; apela al pensamiento puro como facultad de las esencias. Lo que el arte nos permite recobrar es el tiempo tal como se ha enrollado en la esencia [...] Por ello, con todo rigor, sólo la obra de arte nos permite recobrar el tiempo: la obra de arte, «el único medio para recobrar el tiempo perdido». Ella contiene los signos más altos, cuyo sentido está situado en una complicación primordial, eternidad verdadera, tiempo original absoluto, Deleuze (1972: 58).

El recorrido tarkovskiano a través del arte, su necesidad del sacrificio, del amor, de la redención, de la búsqueda de lo absoluto, sea Dios o sea imagen, se acaba trazando en Solaris como una enigmática coreografía siempre desterritorializante. Mientras levitan, mientras se funden las figuras de 
la memoria con las del Quijote, Doré y Brueghel, suena un preludio coral de Bach, en el que también se deja oír solapada una composición de Artemiev. Esta coreografía ${ }^{16}$ de la imagen sigue el ritmo impreciso de la memoria que marca el paso de las revoluciones futuras.

\section{Bibliografía}

ARHEIM, Rudolf (1990): El cine como arte. Barcelona, Paidós.

BAZIN, André (2004): ¿Qué es el cine ?Madrid, Rialp.

BLANCHOT, Maurice (1992): El espacio literario. Barcelona, Paidós.

CERVAntes, Miguel de (1994): Don Quijote de la Mancha. Barcelona, RBA.

De BAECQUe, Antoine (1989): Andrei Tarkovski. Paris, Cahiers du cinema.

DE MAN, Paul. Allegories of reading. New Haven and London, Yale University Press.

Deleuze, Gilles, (1972): Proust y los signos. Barcelona, Anagrama.

- (1983) L'image-temps. Cinéma II. Paris,Minuit.

(1994) Lógica del sentido. Barcelona, Paidós.

Deleuze, Gilles, y Felix GuATTARI (2001): Qué es la filosofía. Barcelona, Anagrama.

DERRIDA, Jacques (1972): Marges de la philosophie. Paris, Minuit.

— (1974) Glas. Paris, Galillée.

(1993): Spectres de Marx. Paris, Galilée.

GARcía Berrio, Antonio, y Teresa Hernández Fernández (1998): Ut poesis pictura. Madrid, Tecnos.

GOVERnATORI, Luca (2002): Andreï Tarkovski, l'art de la pensé. Paris, L'Harmattan.

LYOTARD, Jean-François (1979): Discurso, figura. Barcelona, Gustavo Gili.

MARrati, Paola (2004): Gilles Deleuze. Cine y filosofía. Buenos aires, Nueva Visión.

Metz, Christian (1997): Psicoanálisis y cine. Barcelona, Gustavo Gili.

Mizumura, Minae (1985): «Renunciation», en Peter Brooks, Soshana Felman, y John Hillis

MiLler, eds., «The lesson of Paul de Man», Yale French studies, 69.

Mulvey, Laura (1985): Placer visual y cine narrativo. Valencia, Eutopías.

SeÑor, Carlos (1994): A. Tarkovski. Madrid, Ediciones J. C.

TARKOVSKI, Andrei (2004): Esculpir en el tiempo. Madrid, Rialp.

Turovskaya, Maya (1989): Cinema as Poetry. London, Faber.

UlMER, Gregory (1994): Heuretics. London, The Johns Hopkins University Press.

ŽıžEK, Slavoj (1999): «The thing from inner space on Tarkovsky», Angelaki, 4/3, pp. 221-231.

\footnotetext{
${ }^{16}$ Coreografía o utilizando el término Gregory Ulmer, corografía. Pero una corografía que parte de la Khôra, que no es el objeto de una historia, sino el asiento, el lugar de recepción y desdoblamiento por el que cada historia es un receptáculo, un lugar de inscripción para otro.
} 